\title{
Characterization of Mirror and Polished Surfaces With a Digital Interferometric Measurement System
}

Federal Manufacturing \& Technologies

Paul E. Klingsporn

KCP-613-5961

Published May 1997

Final Report

Approved for public release; distribution is unlimited.
RECEIVED

JUN 091997

OSTI

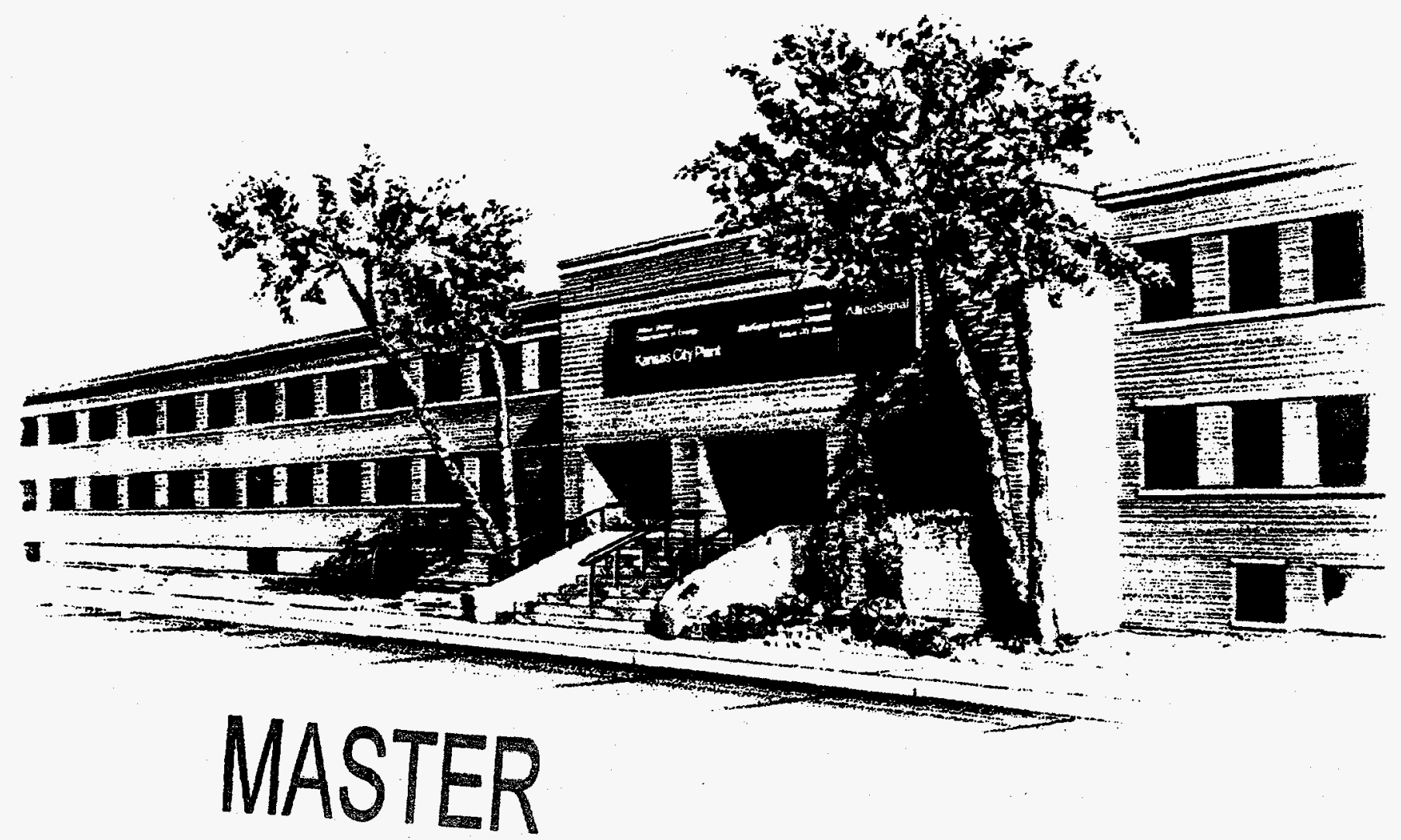

Prepared Under Contract Number DE-ACO4-76-DP00613 for the United States Department of Energy 


\section{DISCLAIMER}

This report was prepared as an account of work sponsored by an agency of the United States Government. Neither the United States Government nor any agency thereof, nor any of their employees, makes any warranty, express or implied, or assumes any legal liability or responsibility for the accuracy, completeness, or usefulness of any information, apparatus, product, or process disclosed, or represents that its use would not infringe privately owned rights. Reference herein to any specific commercial product, process, or service by trade names, trademark, manufacturer, or otherwise, does not necessarily constitute or imply its endorsement, recommendation, or favoring by the United States Government or any agency thereof. The views and opinions of authors expressed herein do not necessarily state or reflect those of the United States Government or any agency thereof.

Printed in the United States of America.

This report has been reproduced from the best available copy.

Available to DOE and DOE contractors from the Office of Scientific and Technical Information, P. O. Box 62, Oak Ridge, Tennessee 37831; prices available from (615) 576-8401, FTS 626-8401.

Available to the public from the National Technical Information Service, U. S. Department of Commerce, 5285 Port Royal Rd., Springfield, Virginia 22161.

A prime contractor with the United States Department of Energy under Contract Number DE-ACO4-76-DP00613.
AlliedSignal lnc. Federal Manufacturing \& Technologies P. O. Box 419159 Kansas City, Missouri 64141-6159 
KCP-613-5961

Distribution Category UC-706

Approved for public release; distribution is unlimited.

\section{CHARACTERIZATION OF MIRROR AND POLISHED SURFACES WITH A DIGITAL INTERFEROMETRIC MEASUREMENT SYSTEM}

Paul E. Klingsporn

Published May 1997

Final Report

Paul E. Klingsporn, Project Leader 


\section{DISCLAMIER}

Portions of this document may be illegible in electronic image products. Images are produced from the best available original document. 
CONTENTS

Section Page

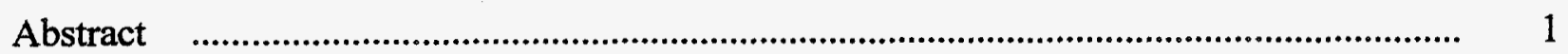

Summary

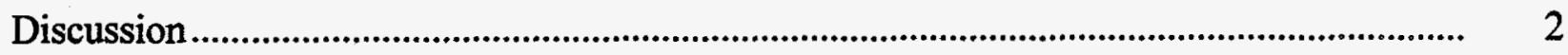

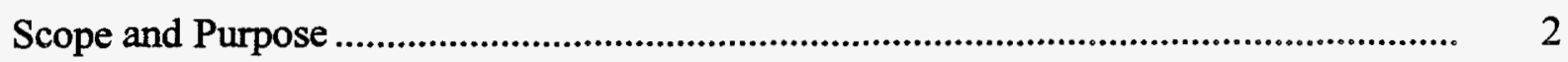

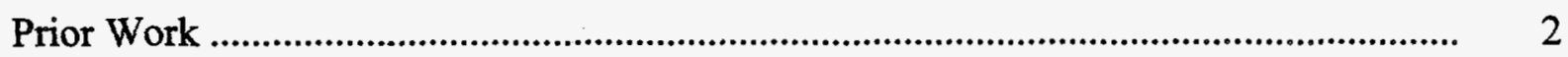

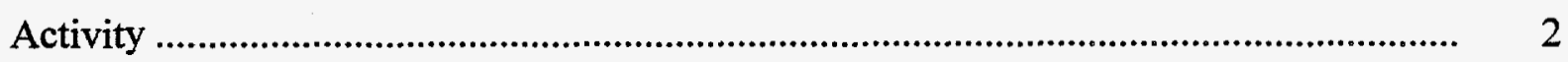

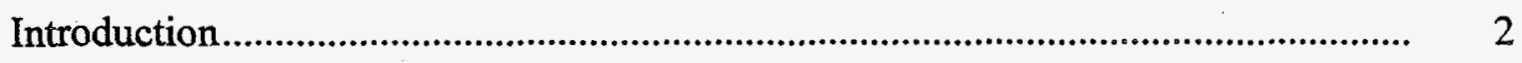

Measurement of a High-Quality Flat Mirror Surface ……........................................ 5

Measurement of a Step-Height Standard ................................................................ 7

Characterization of Polished Nickel Surfaces........................................................ 10

Characterization of Polished Gold Surfaces ............................................................ 11

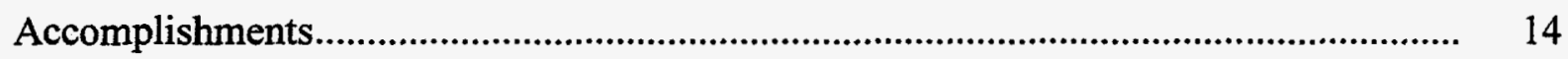




\section{ILLUSTRATIONS}

$\begin{array}{lll}\text { Figure Page } & \text { Pag }\end{array}$

1 Schematic Representation of the WYKO TOPO-2D Optical Digital

Interferometric Surface Measurement System...................................................... 3

2 Hypothetical Surface Profile Illustrating the Three Measures of Surface

Roughness - AA, rms, and Peak-to-Valley

3 Hypothetical WYKO Profile Data Obtained on a Cylindrical or

Spherical Surface, Showing How PV, AA, and rms Are Not Accurate

Unless Curvature Is Removed

4 WYKO Surface Profile Data From a High-Quality Flat Mirror

5 Copy of WYKO Measurement on the Step-Height Standard

6 Copy of a Second WYKO Measurement on the Step-Height Standard

7 WYKO Surface Profile Data From a Final-Finish Nickel Spherical Surface

8 WYKO Measurements of Surface Roughness (AA and rms) Made on

Three Nickel Spheres Polished to Different Levels of Surface Quality

9 WYKO Measurements of Surface Roughness (AA and rms) Made on Three

Gold Spherical Surfaces Polished to Different Levels of Surface Quality

\section{TABLES}

Number

Page

1 Three Different Measures of Surface Roughness Obtained With the WYKO System for Each of Three Nickel Spheres Polished to Different Levels of Surface Quality

2 Standard Deviation and Its Percentage of the Average Value for Each of the Measures of Surface Roughness Data Given in Table 1 


\begin{abstract}
An optical digital-interferometric surface profile measurement system was used for quantitative assessment of the smoothness of polished nickel and gold spherical surfaces. Measurements were made after each of the last three polishing steps on the nickel spheres and after each of the three polishing steps on the gold spheres. Results of the interferometric measurement system were compared with those of a step-height standard certified by the National Institute for Standards and Technology (NIST).
\end{abstract}

\title{
SUMMARY
}

A system using white-light digital interferometry was used to measure the surface finishes of a high-quality flat mirror, a step-height standard, and spherical nickel and gold surfaces at different stages of polish. The flat mirror had a measured profile characterized by a peak-to-valley height of $1.65 \mathrm{~nm}$ (16.5 angstroms) and a root-mean-square ( $\mathrm{rms}$ ) value of $0.268 \mathrm{~nm}$ (2.68 angstroms). The step-height standard had a height certified at 163 angstroms, and the measured results were in excellent agreement. Measurements on the nickel spheres gave rms values in the range 0.086 to 0.332 microinch, depending on the level of polish. For the gold spheres, the measured rms values were in the range of 0.195 to 0.460 microinch. 


\section{DISCUSSION}

\section{SCOPE AND PURPOSE}

An optical digital-interferometric system was used to measure the surface smoothness of nickel and gold spheres for comparison with earlier empirical correlations between measured reflected light level and mechanical stylus profilometer surface measurements.

\section{PRIOR WORK}

In earlier work, reflected and diffracted light intensities were measured when nickel and gold spheres were illuminated with a laser beam. The measured intensity distributions were correlated with surface roughness measurements made with a mechanical-contact stylus profilometer.

\section{ACTIVITY}

\section{Introduction}

Traditional methods of measuring surface profiles utilize a technique in which a small diamond or sapphire spherical tip is dragged along the test surface over a prescribed length. To a greater or lesser extent, the small tip follows the surface contour peaks and valleys, and through appropriate calibration, the excursions of the tip are converted to a height vs. distance profile of the surface.

A schematic of an optical non-contact digital interferometric profilometer is shown in Figure 1. This is a "WYKO TOPO 2D" system, which uses white light illumination to eliminate spurious interference fringes from stray reflections in laser-illuminated systems. The objective has built into it an interferometer with an internal reference surface - the uniqueness of a "Mirau" interferometer. Light reflected from the surface under test interferes with light reflected from the internal reference surface, and the resulting interference pattern is viewed through the eyepieces of the microscope. The interference pattern is also recorded by the image sensor and digitized by the computer. Deviations of the fringe pattern are related to surface height deviations.

The Mirau interferometer is mounted on a piezoelectric translator (PZT) that is moved under computer control. Computerized movement of the interferometer via the PZT introduces a known phase shift in the interferometer, and this is simultaneously recorded. The computer software converts movement of the interference fringe pattern to surface height deviations. The entire measurement cycle occurs in only a few tenths of a second. 


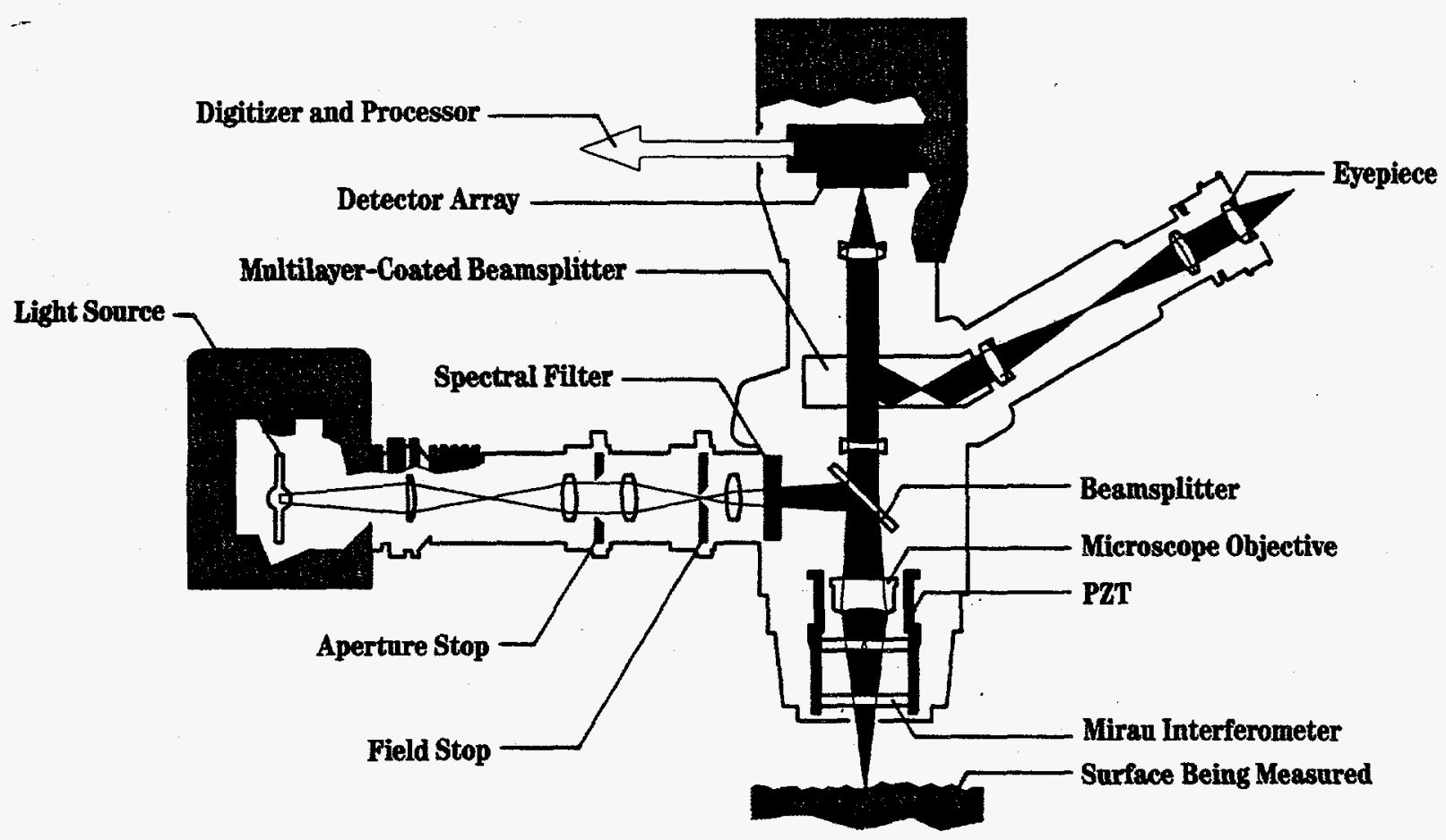

Figure 1. Schematic Representation of the WYKO TOPO-2D Optical Digital Interferometric Surface Measurement System (WYKO Corp., Tucson, AZ)

The TOPO-2D system has a profile measurement length of $0.666 \mathrm{~mm}$, and the spatial sampling interval is $0.65 \mu \mathrm{m}$. That is, the measurement process occurs over a small rectangle in the plane of the surface that has dimensions of $0.666 \mathrm{~mm}$ length and $0.65 \mu \mathrm{m}$ width. The optical resolution in the plane of the surface is $0.81 \mu \mathrm{m}$. The optical resolution of the TOPO-2D system in the plane perpendicular to the surface (i.e., in the surface profile) is in the angstrom $\left(10^{-8} \mathrm{~cm}\right.$ or $3.937 \times 10^{-3}$ microinch) range.

In fact, the repeatability of the TOPO-2D system for profile height measurements is $0.01 \mathrm{~nm}$ ( 0.1 angstrom), or approximately $4 \times 10^{-4}$ microinch root-mean-square $(\mathrm{rms})$ when the system is properly isolated from floor vibrational effects.

The WYKO TOPO-2D system is upgradable to a 3D system, but at a sacrifice in optical resolution.

\section{Surface Roughness Descriptions}

The WYKO system provides three different but somewhat related measures of surface profile roughness. These measures are referred to as arithmetic average (AA), peak-to-valley (PV), and rms. They can be understood with reference to Figure 2, which shows a hypothetical surface profile. 


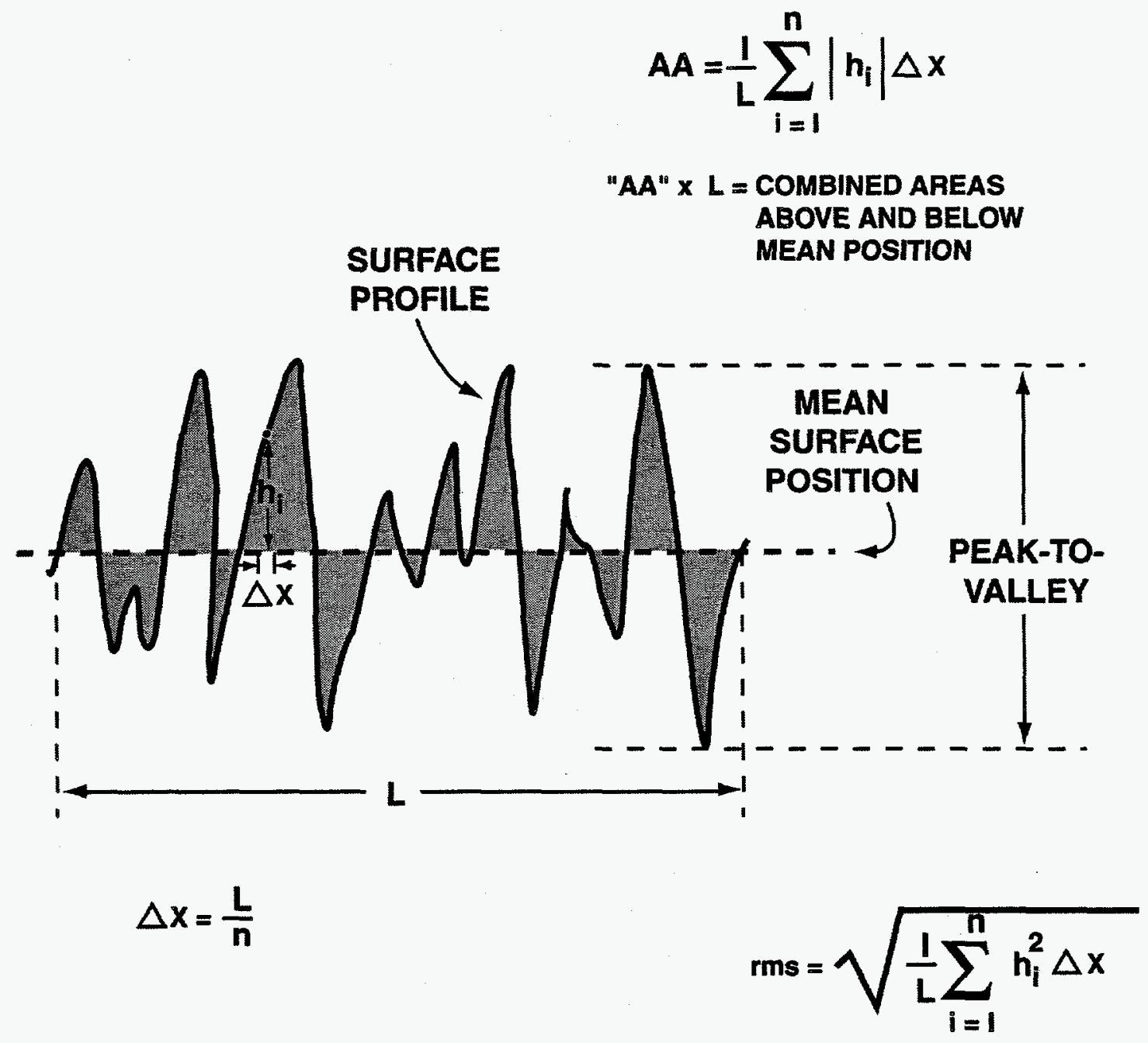

Figure 2. Hypothetical Surface Profile Illustrating the Three Measures of Surface Roughness - AA, rms, and Peak-to-Valley

Over a distance $\mathrm{L}$ along the surface, imagine a line drawn that represents the mean position of the surface. The arithmetic average surface roughness is the height of a rectangle, of length $\mathrm{L}$, that has the same area (AA x L) as the combined areas under the surface profile above and below the mean position. Mathematically, this amounts to dividing the interval $L$ into a large number, $n$, of segments of equal width $\Delta \mathrm{x}=\mathrm{L} / \mathrm{n}$; adding up the products of the profile heights times $\Delta \mathrm{x}$; and dividing the sum by $\mathrm{L}$. That is,

$$
A A=\frac{1}{L} \sum_{i=1}^{n} h_{i} \Delta x
$$


The root-mean-square measure of the surface profile is determined in a similar manner, except that it is the sum of the products of the square of the profile height above or below the mean line at each point that is summed; then the square root of the sum gives the rms surface value.

$$
r m s=\sqrt{\frac{1}{L} \sum_{i=1}^{n} h_{i}^{2} \Delta x}
$$

Finally, the peak-to-valley measure of surface roughness, over a given length $L$ along the surface, is merely the difference between the highest profile point and the lowest profile point.

$$
P V=h_{\max }-h_{\text {min }} .
$$

In the latter, the proper sign of $h_{\min }$ must be used. For example, if $h_{\max }$ is $3 \mu$ in. and $h_{\min }$ is $-1.7 \mu$ in., then $\mathrm{PV}=4.7 \mu$ in.

\section{Surface Contour}

The foregoing discussion assumed a flat surface. The WYKO system has software routines for dealing with a non-flat surface. For example, if profile roughness data is obtained on a cylinder in a plane perpendicular to the axis of the cylindrical surface, or on a sphere in a plane passing through the spherical center, then Figure 3 gives a hypothetical plot of the data. The profile roughness data is superimposed on a circular arc representing a portion of a circle in these two cases. To remove "curvature" from the data, the WYKO system software routine performs a best-fit mathematical circle to the raw data and then subtracts, point-for-point, the arc of a circle from the data to in effect "flatten out" the profile data for surface roughness analysis. The radius of curvature of the best-fit circle is displayed by the WYKO system as "RC."

\section{Measurement of a High-Quality Flat Mirror Surface}

The WYKO company provided a high-quality flat mirror to use as a reference with the system. Figure 4 shows a plot of the surface profile measurements on the mirror, obtained with the WYKO system. For this plot, the field of view is $298 \mu \mathrm{m}$ in diameter, as can be seen on the horizontal scale (that is, $\mathrm{L}=298 \mu \mathrm{m}[0.0117 \mathrm{inch}]$ in the earlier discussion related to Figure 2). For the particular display in Figure 4, the vertical scale on the surface profile is in nanometers. (Note that $1 \mathrm{~nm}=10$ angstroms $=0.03937 \mu$ inch.) From the data in the upper left of Figure 4, the high-quality flat mirror has a profile roughness characterized by $\mathrm{AA}=0.206 \mathrm{~nm}(2.06 \AA)$ and $\mathrm{rms}=0.268 \mathrm{~nm}(2.68 \AA)$. The AA value is referred to as "RA" in the display of Figure 4 . In the upper right corner of Figure 4, the peak-to-valley is given as $P V=1.65 \mathrm{~nm}(16.5 \AA)$, and this can be verified by observing the algebraic difference between the height of the maximum peak and the depth of the minimum valley in the profile display. 


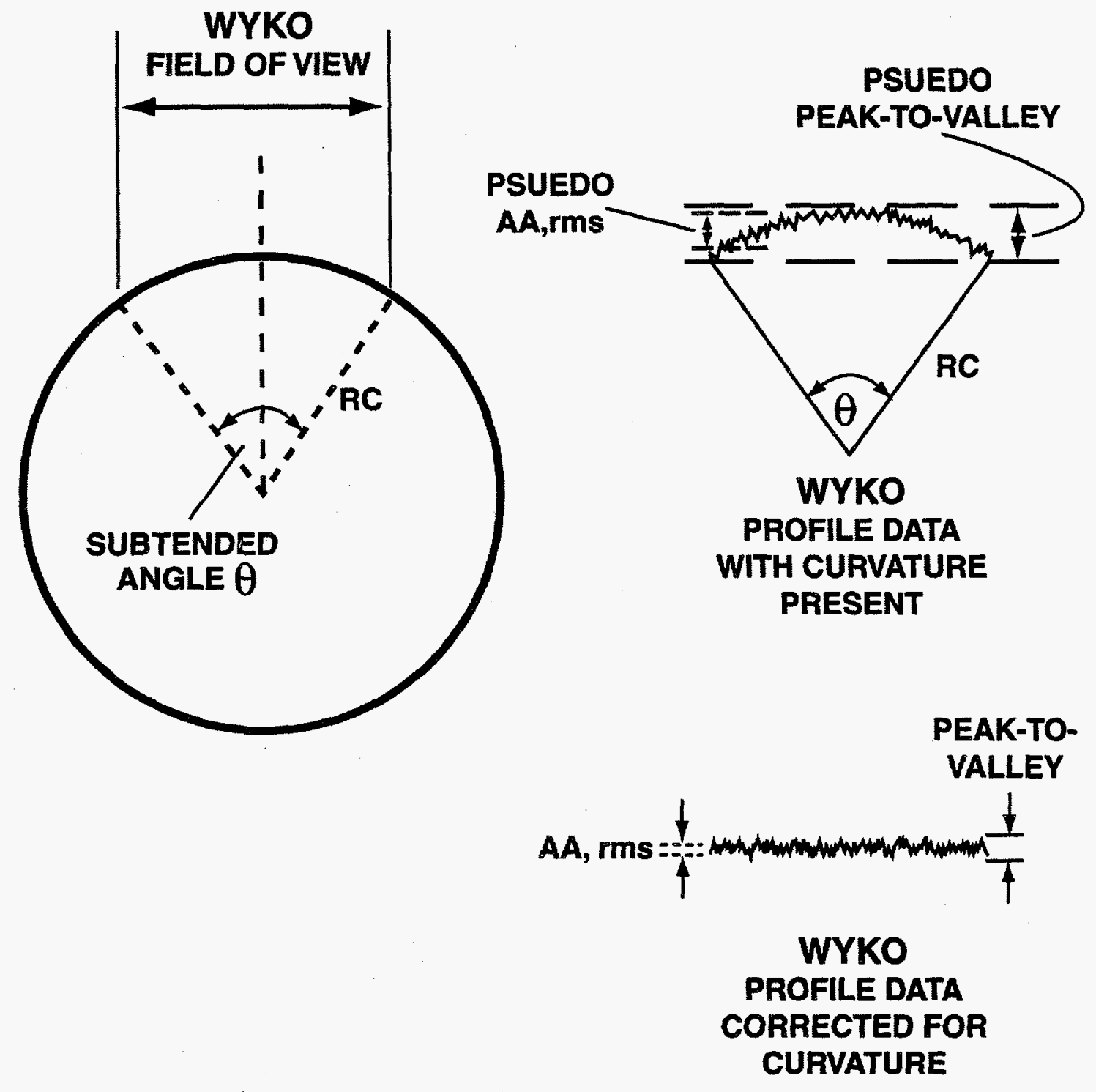

Figure 3. Hypothetical WYKO Profile Data Obtained on a Cylindrical or Spherical Surface, Showing How PV, AA, and rms Are Not Accurate Unless Curvature Is Removed 


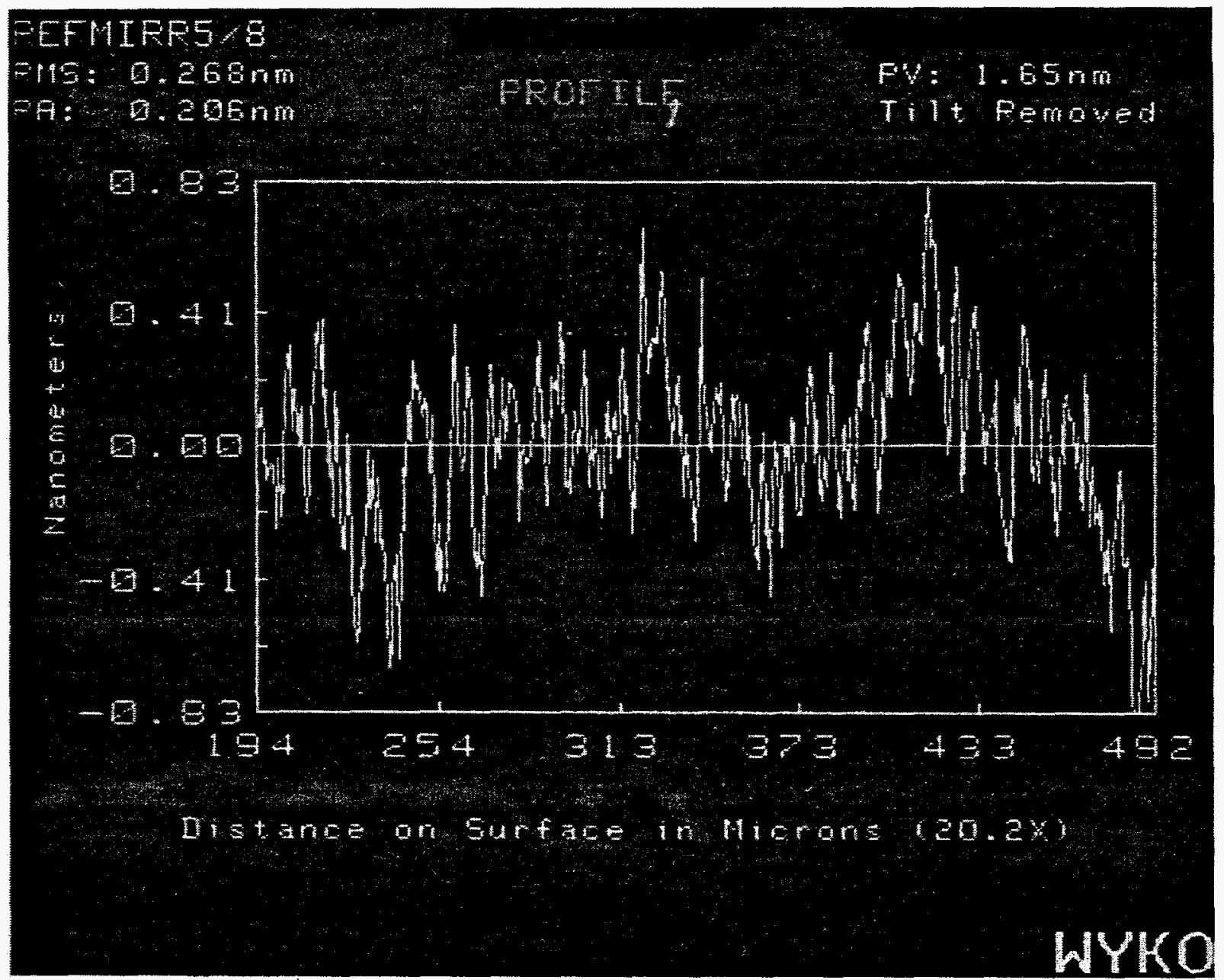

Figure 4. WYKO Surface Profile Data From a High-Quality Flat Mirror

\section{Measurement of a Step-Height Standard}

A step-height standard was obtained from VLSI Standards, Inc. (Mountain View, CA). The step material is chromium-coated silicon dioxide on silicon dioxide. The step height is 163 angstroms, with a step uniformity of 5 angstroms and a total uncertainty of 10 angstroms (one sigma). The reference standard is National Institute for Standards and Technology (NIST) Test No. 731/244040-90. The calibration is in compliance with MIL-STD-45662A, and the environmental conditions at the time of calibration were temperature, $23^{\circ} \mathrm{C}$, and relative humidity, 45 percent.

The WYKO TOPO-2D system was used to obtain surface profiles of the step-height standard. Two measurements were made, and copies of the actual traces are shown in Figures 5. and 6. Taking into account the vertical scale, the measured height of the step from Figure 5 is $162.97 \AA \pm 3.4 \AA$. From Figure 6, the measured step height is $162.9 \AA \pm 4.7 \AA$. Both measurements are in excellent agreement with the NIST-calibrated step height. 


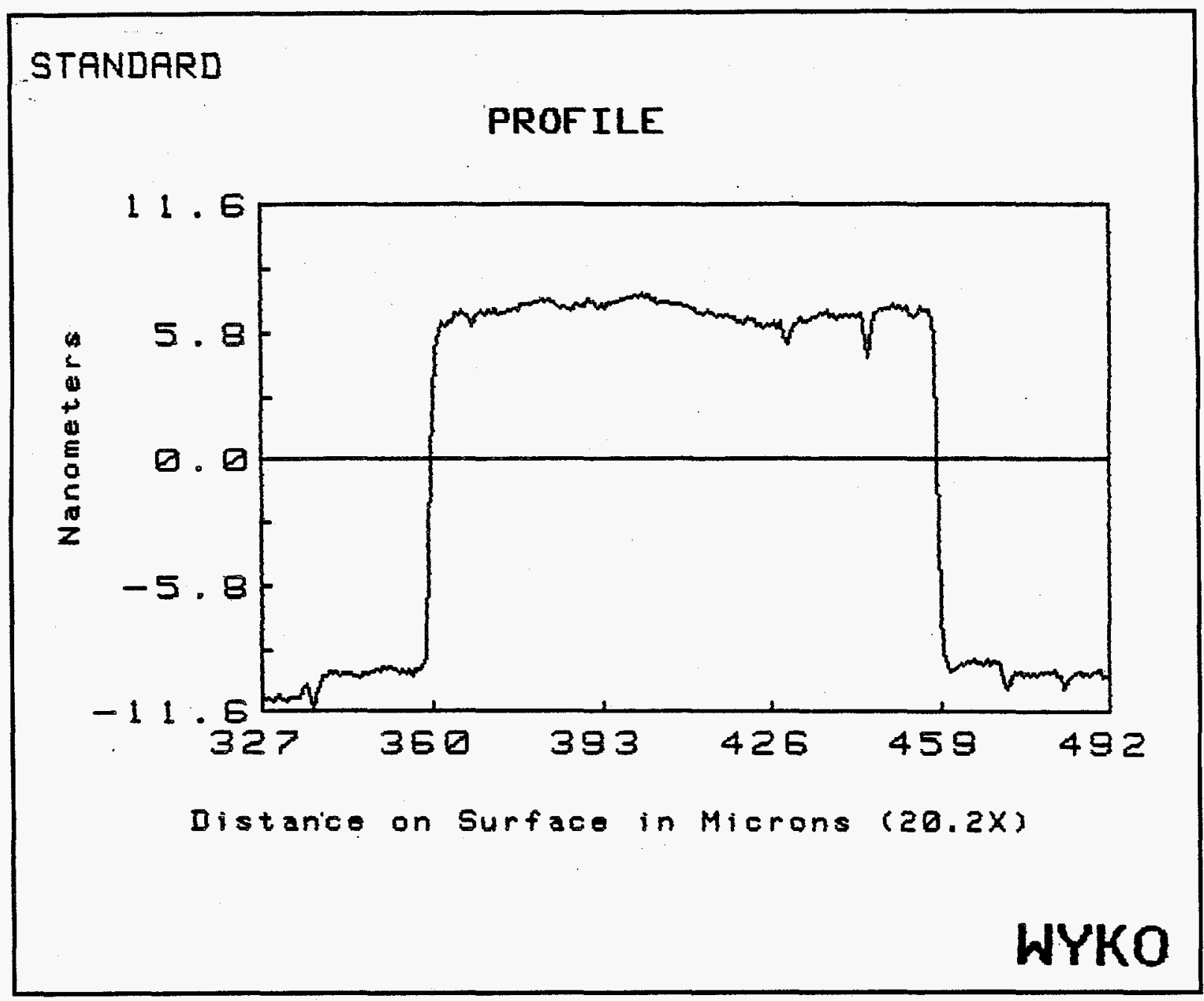

Figure 5. Copy of WYKO Measurement on the Step-Height Standard 


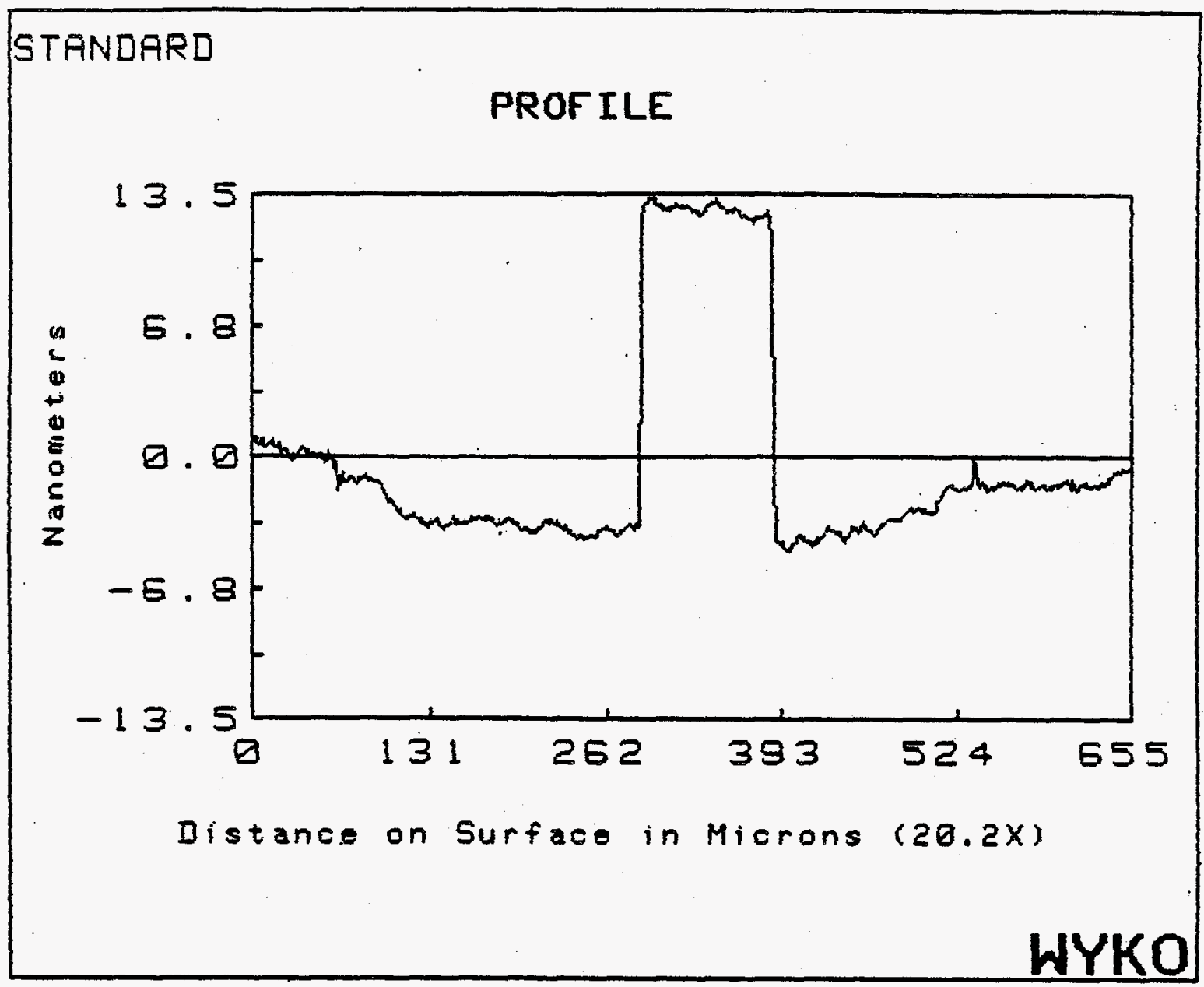

Figure 6. Copy of a Second WYKO Measurement on the Step-Height Standard (Note: both the horizontal and vertical scales are different from those in the measurement data presented in Figure 5.) 


\section{Characterization of Polished Nickel Surfaces}

Surface roughness measurements were made on each of three nickel spheres, each polished to a different level of surface quality. Each sphere was measured at ten different arbitrary locations on the surface. A representative profile obtained at an arbitrary location on the best-polished sphere is given in Figure 7. The data in Figure 7 are corrected for curvature, as discussed earlier. Note that the profile distance is $0.0118 \mathrm{inch}$, the same as on the reference mirror. The vertical scale for the nickel sphere is in microinches, and Figure 7 shows that the surface profile is characterized by $\mathrm{AA}=0.067 \mu \mathrm{in} .(17.0 \AA), \mathrm{rms}=0.088 \mu \mathrm{in} .(22.3 \AA)$, and $\mathrm{PV}=0.478 \mu \mathrm{in}$. (121 A).

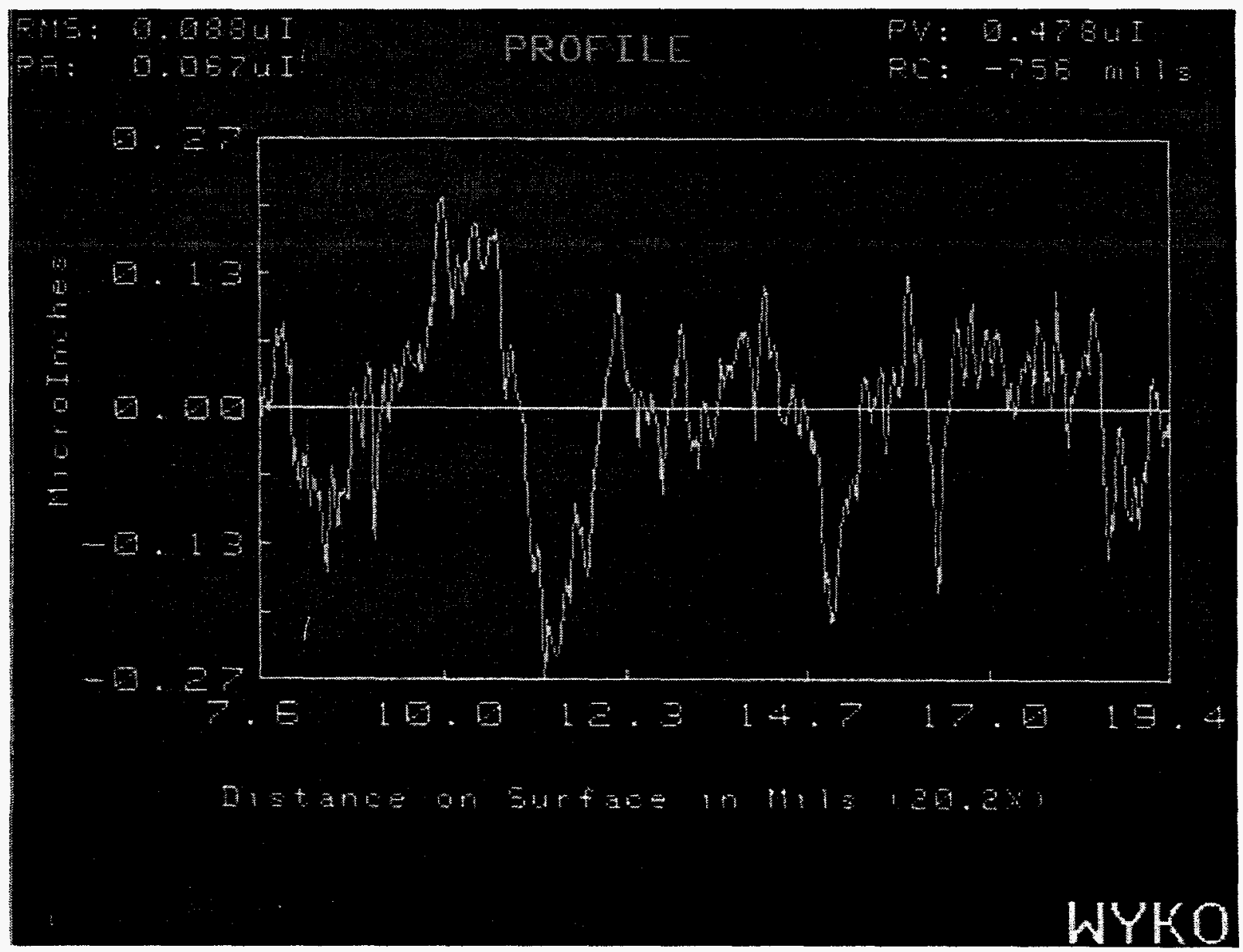

\section{Figure 7. WYKO Surface Profile Data From a Final-Finish Nickel Spherical Surface}

Table 1 gives the average values of the ten measurements made on each of the three nickel spheres. Some variation exists from location to location on each sphere and, to assess this, the standard deviation was calculated for the measurements on each nickel sphere. These are given in Table 2, along with the percentage of the mean or average value. Note that the AA and rms roughness values vary by approximately 12 to 15 percent over the surface, at the $1 \sigma$ level. The percent variation in $\mathrm{PV}$ is a little greater, ranging from 8.5 to 24.6 percent among the three spheres. 
Even though there is some variation from region to region on each of the three nickel spheres, each of the three surfaces is distinctly different from the others at the $\pm 2 \sigma$ level. This is represented graphically in Figure 8, which gives a plot of AA $\pm 2 \sigma$ and $\mathrm{rms} \pm 2 \sigma$ as obtained from the data of Tables 1 and 2.

Table 1. Three Different Measures* of Surface Roughness Obtained With the WYKO System for Each of Three Nickel Spheres Polished to Different Levels of Surface Quality

\begin{tabular}{|l|l|l|l|}
\hline Process & Anthmetic Average & Root-Mean-Square & Peak-to-Valley \\
\hline Full Polish & $0.067 \mu \mathrm{inch}$ & $0.086 \mu \mathrm{inch}$ & $0.521 \mu \mathrm{inch}$ \\
\hline Omit Last Step & $0.141 \mu \mathrm{inch}$ & $0.176 \mu \mathrm{inch}$ & $0.979 \mu \mathrm{inch}$ \\
\hline Omit Last Two Steps & $0.262 \mu \mathrm{inch}$ & $0.332 \mu \mathrm{inch}$ & $1.913 \mu \mathrm{inch}$ \\
\hline
\end{tabular}

* Each entry is an average of measurements made at 10 arbitrary locations on the surfaces of the nickel spheres.

Table 2. Standard Deviation and Its Percentage of the Average Value for Each of the Measures of Surface Roughness Data Given in Table 1

\begin{tabular}{|l|c|c|c|c|c|c|}
\hline Procesc & \multicolumn{2}{|c|}{ Arithmetic Average } & \multicolumn{2}{c|}{ Root-Mean-Square } & \multicolumn{2}{c|}{ Peals-to-Valley } \\
\hline & & $\%$ of Mean & & $\%$ of Mean & \% of Mean \\
\hline Full Polish & $0.010 \mu \mathrm{inch}$ & 14.9 & $0.012 \mu \mathrm{inch}$ & 14.0 & $0.128 \mu \mathrm{inch}$ & 24.6 \\
\hline $\begin{array}{l}\text { Omit Last } \\
\text { Step }\end{array}$ & $0.019 \mu \mathrm{inch}$ & 13.2 & $0.021 \mu \mathrm{inch}$ & 11.9 & $0.083 \mu \mathrm{inch}$ & 8.5 \\
\hline $\begin{array}{l}\text { Omit Last } \\
\text { Two Steps }\end{array}$ & $0.031 \mu \mathrm{inch}$ & 11.7 & $0.042 \mu \mathrm{inch}$ & 12.6 & $0.330 \mu \mathrm{inch}$ & 17.3 \\
\hline
\end{tabular}

\section{Characterization of Polished Gold Surfaces}

The WYKO system was used to assess surface roughness on each of three gold spherical surfaces, each polished to a different level of smoothness. As in the case of the nickel surfaces, measurements were made at ten arbitrary locations on each surface. Some variation over a given surface exists, and this can be seen from the $\pm 2 \sigma$ limits for each surface in the graphical presentation of the data in Figure 9. It is interesting that the next-to-last polishing step with 3-OS diamond slurry did not improve the surface relative to the previous step with 6-OS diamond slurry. Overall, the gold surface at the final polishing is not quite as smooth as the nickel at final polish. This may be because the gold is much softer than nickel and relatively more prone to residual micro-scratches. 


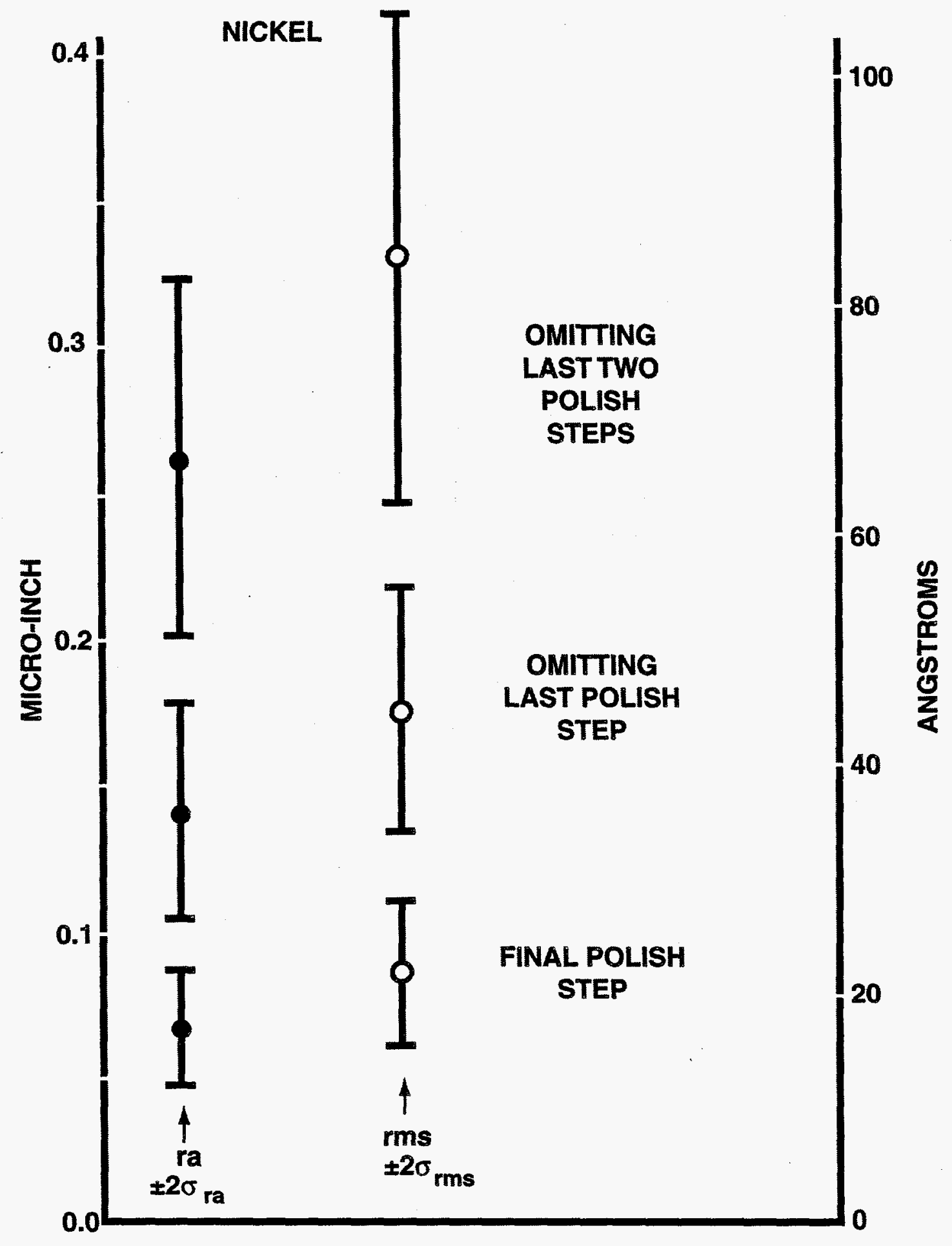

Figure 8. WYKO Measurements of Surface Roughness (AA and rms) Made on Three Nickel Spheres Polished to Different Levels of Surface Quality (The bars representing $\pm 2 \sigma$ limits reflect the fact that the surfaces vary from location to location.) 


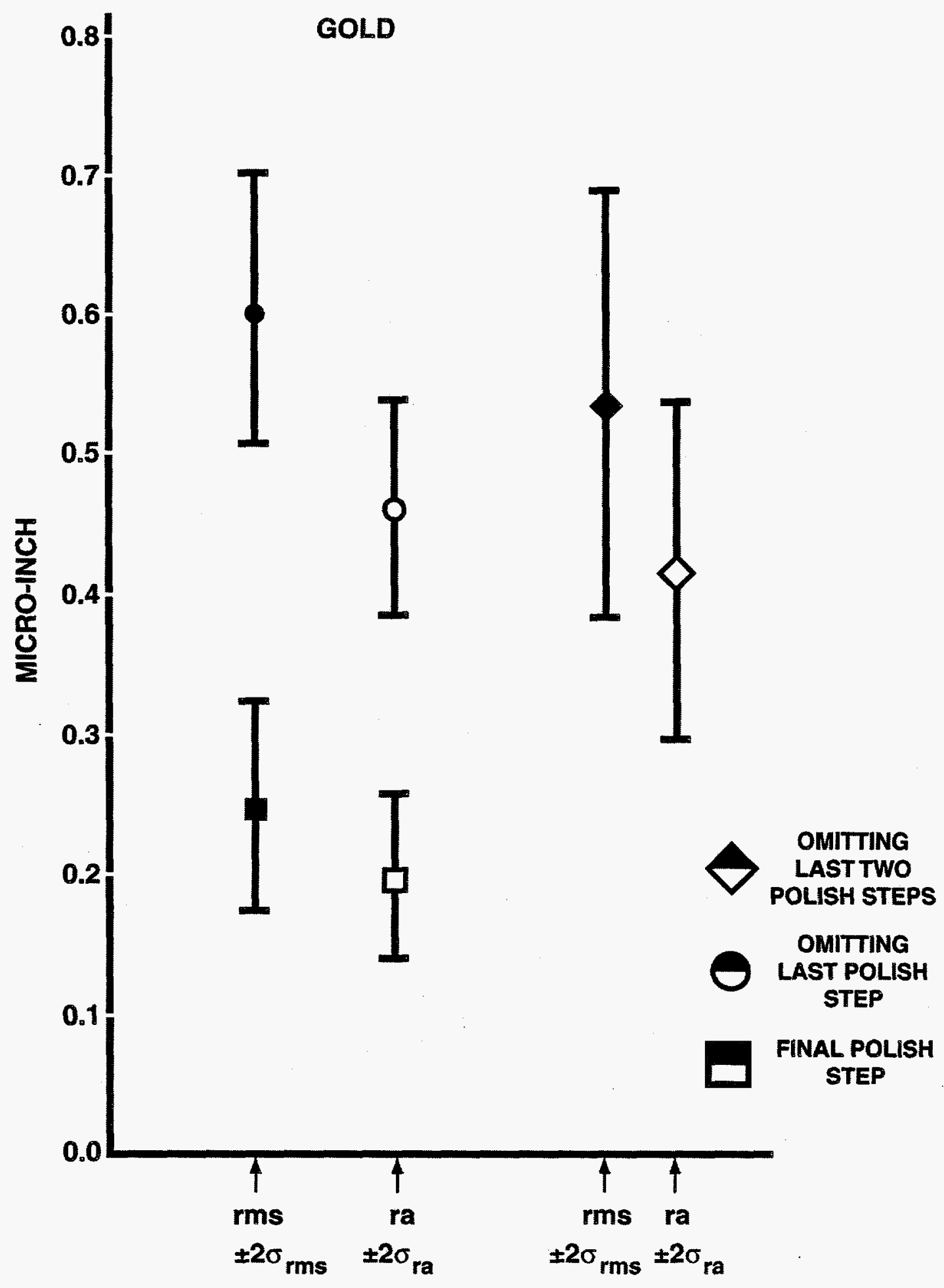

Figure 9. WYKO Measurements of Surface Roughness (AA and rms) Made on Three Gold Spherical Surfaces Polished to Different Levels of Surface Quality (The bars representing $\pm 2 \sigma$ limits indicate the variation from one region to another on the surface.) 


\section{ACCOMPLISHMENTS}

A non-contact optical digital interferometric measurement system was used to characterize a variety of surfaces. Measurements on a high-quality flat mirror showed a peak-to-valley height of 16.5 angstroms, with an rms value of 2.6 angstroms. Measurements on an NIST-calibrated step-height standard gave a height of 162.9 angstroms \pm 4.7 angstroms, in excellent agreement with the NIST certification.

Measurements on nickel spheres at three different levels of polish in the range below 0.4 microinch $\mathrm{rms}$ showed that the effects of polishing yielded surface improvement at the $\pm 2 \sigma$ level in the final polishing steps. On gold spheres, improved surface smoothness was measured at the $\pm 2 \sigma$ level on the final polishing step, relative to the next-to-last step. 